CDD: 004.678

\title{
POLítICAS PÚBLICAS DE INFORMAÇÃO NO CONTEXTO DA INCLUSÃO E GESTÃO DA INFORMAÇÃO: UMA ANÁLISE SOBRE AS POLíTICAS PÚBLICAS DA SECRETARIA MUNICIPAL DE EDUCAÇÃO DE JUAZEIRO DO NORTE - CE
}

\author{
PUBLIC POLICIES OF INFORMATION IN THE CONTEXT OF INCLUSION AND \\ INFORMATION MANAGEMENT: AN ANALYSIS OF PUBLIC POLICIES OF THE \\ MUNICIPAL EDUCATION JUAZEIRO - CE
}

\section{Naira Michelle Alves Pereira', Jonathas Luiz Carvalho Silva ${ }^{2}$}

\begin{abstract}
RESUMO: O presente trabalho tem por objetivo investigar percepções referentes às políticas públicas de informação no contexto das políticas públicas de educação da Secretaria Municipal de Educação de Juazeiro do Norte/CE. A metodologia do presente artigo foi estabelecida quanto aos fins como sendo de cunho exploratório e descritivo, pois se busca estabelecer uma possível interpolação das políticas públicas de informação no âmbito das políticas públicas de educação existentes na Secretaria Municipal de Educação de Juazeiro do Norte/CE. Quanto aos meios, a pesquisa classifica-se como sendo bibliográfica e documental, uma vez que foi realizada revisão da literatura para construção do referencial teórico e utilizados documentos disponibilizados nos portais de comunicação do governo federal, estadual e municipal, para descrever e analisar as políticas públicas em estudo. No que se refere à natureza dos dados, sua análise foi realizada por meio de uma abordagem qualitativa a partir da aplicação de entrevistas junto aos coordenadores responsáveis pelo gerenciamento das políticas públicas em estudo. Considera-se que o município de Juazeiro do Norte/CE precisa de investimento por parte do governo em infraestrutura informacional e tecnológica no campo educacional, que garantam o melhor desempenho dos significados informacionais percepcionados no âmbito dessas políticas educacionais.
\end{abstract}

PALAVRAS-CHAVE: Políticas públicas de informação. Políticas públicas de educação. Inclusão. Gestão da informação. Tecnologia de informação e comunicação. Juazeiro do Norte - CE.

ABSTRACT: The present study aims to investigate perceptions related public policy information in the context of public education policies of the Municipal Education Juazeiro/CE. The methodology of this paper was established as being about the purposes of exploratory and descriptive, as it seeks to establish a possible interpolation public policy information within the public education policies in the existing Municipal Education Juazeiro/CE. As for media, research is classified as literature and documents, since we reviewed the literature for the construction of theoretical and documents used in portals of communication available federal, state and local, to describe and analyze public policy under study. Regarding the nature of the data, their analysis was performed using a qualitative approach from the application of interviews with the coordinators responsible for managing public policy under study. It is considered that the municipality Juazeiro/CE needs investment by government in infrastructure and informational technology in education, to ensure the best performance of informational perceived meanings within these educational policies.

KEYWORDS: Public information policies. Public policy education. Inclusion. Information management. Technologies of information and communication. Juazeiro - CE.

\footnotetext{
${ }^{1}$ Bacharela em Biblioteconomia pela Universidade Federal do Ceará, Campus Cariri. Bibliotecária do Instituto Federal de Educação, Ciência e Tecnologia do Sertão Pernambucano. <nairamichelle_ufc@ yahoo.com.br>

${ }^{2}$ Doutorando em Ciência da Informação pela Universidade Federal da Bahia, Brasil. Professor da Universidade Federal do Ceará.jonathascarvalhos@yahoo.com

Submetido em: 26/04/2014 - Aceito em: 04/11/2014
} 


\section{INTRODUÇÃ̃O}

Diante do novo quadro econômico mundial, em que a informação ganhou importante influência política, cultural, social e ideológica frente ao processo de produção do capital intelectual do Estado contemporâneo, bem como da sua produção econômica, observa-se a importância e as exigências atribuídas ao Estado, governos e sociedade, sobre o desenho do arcabouço de novas discussões na agenda política, bem como na elaboração de políticas públicas capazes de responder e atender as transformações sociais, ocasionadas pelas complexidades informacionais contemporâneas.

Nesse cenário, surgem as políticas de informação como instrumento e fator estratégico do Estado contemporâneo para intervenção, bem como consolidação de estruturas de informação para o desenvolvimento social, tendo como seu campo de domínio a ciência e a tecnologia.

Face ao exposto, pode-se dizer que o desenvolvimento científico-tecnológico tem influenciado significativamente fatores históricos, culturais e educacionais evidenciando a necessidade de se pensar as relações existentes entre informação e educação no cenário que envolve atividades cada vez mais complexas, em termos de apropriação de informação e construção de conhecimento, a partir de saberes e fazeres "como condição de sobrevivência e participação no universo do conhecimento e da cultura" (PERROTI; PERUCCINI, 2007, p. 51).

Nessa perspectiva, entende-se aqui que as políticas públicas sociais são um dos principais instrumentos de integração entre Estado, governos e sociedade, e por isso, tornase indispensável entender as relações entre política pública e política de informação, percebendo que as políticas de informação podem estar interpoladas no âmbito de outras políticas públicas, no caso desse trabalho, nas políticas públicas de educação.

Para tanto, foram estabelecidas categorias (inclusão digital, inclusão e acessibilidade e gestão da informação) com o propósito de contextualizar as políticas públicas de informação no âmbito das políticas públicas de educação da Secretaria Municipal de Educação de Juazeiro do Norte - CE, como termo de comparação e/ou caracterização, objetivando evidenciar os significados informacionais presentes no âmbito dessas políticas.

Nessas circunstâncias apresenta-se o seguinte questionamento: Quais as possíveis relações entre as políticas públicas de informação e educação a partir das percepções e 
significados informacionais presentes nas políticas públicas sociais da Secretaria Municipal de Educação de Juazeiro do Norte?

O presente artigo tem por objetivo, investigar percepções referentes às políticas públicas de informação no contexto das políticas públicas de educação da Secretaria Municipal de Educação de Juazeiro do Norte.

\section{POLíticas públicas de INFORMaÇÃo}

A sociedade contemporânea na qual nos situamos, têm caracterizado novos processos sociais em ocasião da aceleração do desenvolvimento impulsionado pelas novas vinculações políticas da informação tanto na ordem econômica quanto social.

Silva (1991, p. 9) explica que

o contorno da economia mundial é traçado, agora, pela quantidade de informação possuída, veiculada e divulgada, resultante da produção científica e tecnológica, que por sua vez significa novos "inputs" alimentando o ciclo.

Dito de outra forma, isso significa dizer que esse novo paradigma social, estabelece nas dimensões históricas, culturais, econômicas, tecnológicas, sociais e políticas précondições para o entendimento do papel da informação (RIBAS; ZIVIANI, 2007).

Por isso, para Ferreira (2003, p. 36-37) aos diversos atores sociais cabem novas responsabilidades no que tange a informação a fim de garantir o pleno desenvolvimento social, econômico e político das sociedades, isso porque:

[...] No que concerne ao desenvolvimento, ela pode viabilizar a elaboração, implementação e avaliação de políticas públicas com maior grau de eficácia e eficiência, a partir da análise da complexidade social em suas demandas e contradições. Assim, para os diferentes atores da sociedade, a informação assume finalidades específicas. [...] [Partindo desse pressuposto], [...] a informação no contexto do Estado está voltada para a análise da realidade social e subseqüente elaboração, aplicação e controle de políticas públicas que promovam o bem-estar da coletividade. Para a sociedade civil, o acesso à informação tem como propósito desenvolver o potencial criativo e intelectual dos indivíduos; entreter; dar sentido às ações dos homens no cotidiano; tornar públicas as proposições políticas e decisões que, tomadas na esfera do Estado, têm reflexos diretos sobre a qualidade de vida das populações. E, de um modo geral, permitir o exercício da cidadania [...].

Nesse quadro, surgem as políticas públicas de informação como consequência das novas configurações políticas da contemporaneidade. Sobre isso, Jardim, Silva e Nharreluga (2009, p. 4) enfatizam que: 
Política de informação tem sido identificada historicamente como um tema emergente após a Segunda Guerra Mundial, especialmente em países de capitalismo central. A sua configuração tem se caracterizado por diversas vinculações políticas da informação e em contextos variados. O cenário privilegiado no qual o tema adquire nitidez teórica e desdobramento operacional são as estruturas do Estado, as características da sociedade civil, as formas de governo e de ser governado nos âmbitos local, regional, nacional e até mesmo transnacional.

Nessa perspectiva, muitos são os conceitos derivados do termo "políticas de informação". Carvalho (2010) destaca uma característica importante das políticas de informação, seu caráter público e privado, estabelecendo dessa forma as diferenças entre as 'políticas públicas de informação' e a 'política de informação':

A política de informação agrega valor a uma instituição, seja ela pública ou privada. No caso das instituições públicas, pode ser um diferencial para que a política pública funcione verdadeiramente. Dentro dessa vertente, [...] o que chamamos de política de informação, [torna-se] a ação pública para o uso da informação.

Apesar disso, Carvalho (2010, p. 82) esclarece que "a literatura sobre política pública de informação é um tanto escassa e, muitas vezes, passa a ser confundida com política de informação, que são as ações das organizações, majoritariamente privadas".

Portanto, compreende-se aqui que o termo políticas de informação pode designar ações de instituições tanto de caráter público quanto de privado, contudo o que buscamos evidenciar no termo 'política de informação' são suas ações em âmbito governamental, estabelecendo sua relação com as políticas públicas.

Assim sendo, de acordo com Branco (2006, p. 199):

Como política pública, a política de informação assenta-se entre interesses e metas políticas e burocráticas, não necessariamente congruentes, manifestando-se para além do aparato governamental. Nesse sentido, a expressão de uma política de informação ultrapassa o campo formal das leis e regulamentos, pois também engloba as práticas e ações informais de um determinado contexto em que se misturam pessoas, instituições e interesses, cujas manifestações nem sempre se revelam por mecanismos formais.

Isto é, assim como as políticas públicas são desenvolvidas para serem implementadas em contextos específicos da sociedade, as políticas de informação também dependem dos diversos segmentos e contextos comunitários para se desenvolverem no cotidiano das pessoas, dessa forma, as políticas de informação são direcionadas e desenvolvidas para 
atender necessidades, suprir carências e demandas das comunidades e por isso sua manifestação está para além do aparato governamental, aliás o seu caráter público permite que seu desempenho se multiplique e se inter-relacione entre governo (interesses e metas políticas, tendo como ação concreta a política pública) e sociedade (práticas cotidianas das comunidades: construção de conhecimento e dispositivos para apropriação da informação).

Aliás, como bem afirma González de Gómez (1999, p. 71) a política de informação é:

uma ação dirigida a consolidar a autonomia informacional dos sujeitos coletivos. [Isso porque] [...] a constituição dos universos de informação parte sempre do 'nós' de um sujeito situado, localizado, territorializado, para o qual algo faz ou não faz sentido como informação. Em cada contexto histórico, em cada espaço de ação coletiva, existe um saber local, um sentimento territorializado ou um desejo do que seja um bem coletivo, que formam parte das razões bem fundadas para priorizar, justificar, gerar ou aderir a um valor de informação.

Assim, nota-se que a informação como um construto coletivo promove apropriações individuais e também coletivas, pois, "como agente mediador na produção de conhecimento, a informação qualifica-se, em forma e substância, como estruturas significantes com a competência de gerar conhecimento para o indivíduo e seu grupo" (BARRETO, 1994, p. 2).

Nessas condições, "a informação não é processo, matéria ou entidade separada das práticas e representações de sujeitos vivendo e interagindo na sociedade, e inseridos em determinados espaços e contextos culturais” (MARTELETO, 2002, p. 102).

Sobre isso Pieruccini (2004, p. 28), explica que "os modos de apropriação do conhecimento e de construção de sentidos são afetados diretamente pelos novos contextos socioculturais, obrigando-nos a repensar os processos aí implicados”.

Com efeito, a contextualização das políticas de informação no contexto das políticas de educação dentro dessa dinâmica informacional da contemporaneidade se faz mister, pois acredita-se que essas políticas são dotadas de importantes práticas informacionais e estratégias educativas na construção de sentidos.

Por conseguinte, nesta seção, entende-se a necessidade de conceber uma contextura real que possibilite conceber as políticas públicas de informação no âmbito das políticas públicas de educação da Secretaria Municipal de Educação de Juazeiro do Norte - CE. Para tanto, foram categorizadas nos seguintes âmbitos: inclusão digital, inclusão e acessibilidade e gestão da informação, apresentadas a seguir. Desse modo, pretende-se através desses 
parâmetros, evidenciar e contextualizar os significados informacionais presentes no âmbito dessas políticas.

\subsection{Contexto da inclusão}

Segundo Bonilla (2002, p. 1) “o conceito de inclusão, por si só, é um conceito problemático, visto ser um conceito que vem sendo revisitado e atualizado de forma a vincular-se a cada visão de mundo que perpassa a sociedade."

Isto significa dizer que a inclusão é um processo eminentemente social, pois perpassa por todas as dimensões da vida em sociedade e é permanente, embora não constante, na vida dos sujeitos; aliás, ao se falar em inclusão, logo pensamos em pessoas, portanto, qualquer tipo de inclusão é de fato uma inclusão social. Assim sendo, de acordo com Passerino e Montardo (2007, p. 5):

Considera-se inclusão, portanto, o processo estabelecido dentro de uma sociedade mais ampla que busca satisfazer necessidades relacionadas com qualidade de vida, desenvolvimento humano, autonomia de renda e equidade de oportunidades e direitos para os indivíduos e grupos sociais que em alguma etapa da sua vida encontram-se em situação de desvantagem com relação a outros membros da sociedade.

Dessa forma, trata-se de compreendermos a inclusão, não por um processo de preparação ou adequação de indivíduos para se inserir em contextos sociais, mas de pensarmos uma sociedade inclusiva, onde todos possam ter as mesmas possibilidades e direitos de compartilharem dos processos e contextos sociais aos quais desejem participar.

Segundo pesquisadores da área de educação, essa é a diferença entre: integração ${ }^{3} \mathrm{e}$ inclusão. Não se trata de preparar pessoas para que possam fazer parte das atividades desenvolvidas pela sociedade, trata-se de compreendermos que todos somos parte da sociedade, e por isso, como bem afirma Godoy et al. (2000, passim)

é nosso dever fornecer mecanismos para que todos possam ser incluídos.Uma sociedade aberta a todos, que estimula a participação de cada um e aprecia as diferentes experiências humanas, e reconhece o potencial de todo cidadão, é denominada sociedade inclusiva.

\footnotetext{
${ }^{3}$ A integração nos induz a acreditar que podemos escolher quais seres humanos têm direito a estar nas escolas, nos parques de diversões, nas igrejas, nos ambientes de trabalho, em todos os lugares. É praticado há décadas mas, desde os anos 80, começou a ser questionado pelo então emergente movimento internacional das organizações de pessoas com deficiência (MÍDIA E DEFICIÊNCIA, 2003, p. 19, grifo do autor).
} 
Sabe-se que no Brasil ainda não vivemos plenamente em uma sociedade inclusiva, contudo já são notórios os esforços de muitos grupos do movimento social que lutam por uma sociedade mais democrática, e também do governo, que têm como estratégias de ação a elaboração e implementação de políticas públicas que direcionam a sociedade a pensar e desenvolver melhor a inclusão de todos os cidadãos.

Nessa perspectiva, busca-se apresentar nos itens a seguir este ponto de vista a partir de ações governamentais por meio de políticas públicas de inclusão no âmbito das tecnologias de informação e comunicação (inclusão digital) e educação inclusiva de pessoas com necessidades especiais nos ambientes escolares (inclusão e acessibilidade).

\subsubsection{Inclusão digital}

É notório que o desenvolvimento e utilização das novas tecnologias digitais de informação e comunicação modificaram consideravelmente o comportamento da sociedade contemporânea ao afetar diretamente a dinâmica social em todas as suas instâncias e formas de comunicação, informação e produção de conteúdos.

Para Cabeda (2005, p. 5) "A inclusão digital e alfabetização tecnológica como política pública é um novo desafio para o Estado." Isso porque a desigualdade social no campo das tecnologias digitais de informação e comunicação, oriundas da sociedade da informação, está relacionada não somente em ter acesso aos equipamentos eletrônicos, mas também envolve as questões de aprendizagem do usuário dessas tecnologias de extrair, a partir de sua capacidade cognitiva, o máximo proveito das potencialidades oferecidas por cada instrumento tecnológico digital, de forma que tenham a competência de aprender, prover serviços, informações e conhecimentos, articular redes de produção que permitirão e potencializarão a emergência do novo, a proposição, a efervescência da diversidade (BONILLA, 2002, p. 3).

Isso nos remete ao que hoje se chama "letramento digital", que segundo Silva et al. (2005, p. 33) corresponde em

saber utilizar as Tecnologias de Informação e Comunicação, saber acessar informações por meio delas, compreendê-las, utilizá-las e com isso mudar o estoque cognitivo e a consciência crítica e agir de forma positiva na vida pessoal e coletiva. 
Deste modo, de acordo com Rondelli (2003, p. 1) compreende-se que “inclusão digital [...] é a aprendizagem necessária ao indivíduo para circular e interagir no mundo das mídias digitais como consumidor e produtor de seus conteúdos e processos". O que para Jamboeiro e Silva (2004, p. 156) "significa o exercício de interação indivíduo-máquina, mas, sobretudo, o desenvolvimento de sua capacidade cognitiva."

Partindo dessas premissas,

Tem-se, então, como fundamental, que a inclusão digital deve ser vista sob o ponto de vista ético, sendo considerada como uma ação que promoverá a conquista da "cidadania digital" e contribuirá para uma sociedade mais igualitária, com a expectativa da inclusão social. [...] Neste sentido, entende-se, como ponto de partida do [seu] conceito, o acesso à informação que está nos meios digitais e, como ponto de chegada, a assimilação da informação e sua reelaboração em novo conhecimento, tendo como consequiência desejável a melhoria da qualidade de vida das pessoas. (SILVA et al., 2005, p. 30).

Portanto, a formulação de políticas públicas capazes de contribuir para a aceleração do processo de inclusão digital que visem ao avanço e inserção da sociedade nas novas práticas de informação e comunicação oferecidas pelas tecnologias digitais e à conseqüente inclusão social em todos os seus aspectos e para todos os brasileiros expressa-se como importante estratégia do Estado na tentativa de diminuir as distâncias sociais existentes no país e garantir o acesso democrático aos bens de consumo aos cidadãos, minimizando a exclusão tanto digital quanto social de um grande contingente de brasileiros (SILVA, 2011).

QUADRO 1 - Políticas públicas de educação no contexto da inclusão digital

\begin{tabular}{clc}
\hline $\begin{array}{l}\text { Política } \\
\text { Pública }\end{array}$ & \multicolumn{1}{c}{ Descrição } & $\begin{array}{c}\text { Nível de } \\
\text { Governo }\end{array}$ \\
\hline $\begin{array}{c}\text { Programa } \\
\text { Nacional de } \\
\text { Tecnologia } \\
\text { Educaciona }\end{array}$ & $\begin{array}{l}\text { O Programa Nacional de Tecnologia } \\
\text { Educional (ProInfo), inicialmente }\end{array}$ & \\
I & $\begin{array}{l}\text { Informática na Educação, foi criado } \\
\text { pelo Ministério da Educação, pela }\end{array}$ & Federal \\
(PROINFO & $\begin{array}{l}\text { Portaria no 522, de 9 de abril de } \\
\text { ) }\end{array}$ & $\begin{array}{c}\text { 1997, pelo Ministério da Educação } \\
\text { com a finalidade de promover o uso }\end{array}$ \\
& e acesso das tecnologias de & \\
& informação e comunicação como & \\
& ferramenta de apoio pedagógico no & \\
& ensino público da educação básica. & \\
\hline
\end{tabular}




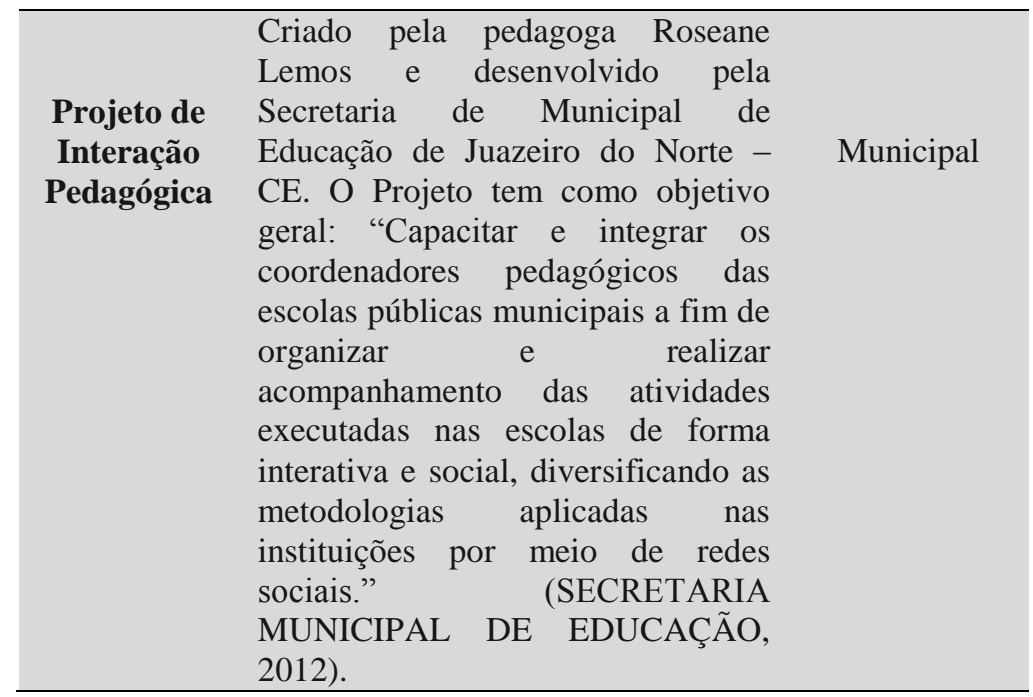

Fonte: Elaborado pelo autor.

\subsubsection{Inclusão e Acessibilidade}

\section{Para Torres, Mazzoni e Alves (2000, p. 83)}

a acessibilidade é um processo dinâmico, associado [...] principalmente ao desenvolvimento da sociedade. Apresenta-se em estágios distintos, variando de uma sociedade para a outra, conforme seja a atenção dispensada à diversidade humana, por essa sociedade, à época.

Dito isto, compreende-se que o conceito de acessibilidade está associado às percepções da sociedade, sobre os significados que envolvem as condições e oportunidades de acesso e uso, por todas as pessoas, dos produtos, serviços, informações e espaços urbanos em geral, valorizando e reconhecendo as suas diferenças.

Segundo Melo (2006, p. 17):

Atualmente existem diferentes entendimentos para a expressão acessibilidade. É bastante comum associá-la primeiramente ao compromisso de melhorar a qualidade de vida dos idosos e de pessoas com deficiência (ex. perceptual, cognitiva, motora e múltipla), uma vez que essas pessoas, em geral, sofrem impacto direto da existência de barreiras nos vários ambientes, produtos e serviços que utilizam. Entretanto, acessibilidade ou possibilidade de alcance aos espaços físicos, à informação, aos instrumentos de trabalho e estudo, aos produtos e serviços diz respeito à qualidade de vida de todas as pessoas. Para o delineamento de uma sociedade mais inclusiva, que reconhece e valoriza as diferenças entre as pessoas, torna-se cada vez mais importante que propostas para a acessibilidade de pessoas com características específicas estejam articuladas à promoção da qualidade de vida para todos.

Assim sendo, compreende-se que o conceito de acessibilidade envolve questões referentes às possibilidades de utilização, seja de espaços físicos, produtos, serviços, informação por qualquer pessoa independentemente de suas limitações. É, portanto, um 
direito de todo cidadão ter de forma acessível aquilo que julgar necessário para o seu desenvolvimento em sociedade.

Em uma visão mais ampla, a publicação Mídia e Deficiência (2003, p. 24-25) destaca seis quesitos essenciais para que uma sociedade seja considerada acessível:

a)

Acessibilidade arquitetônica: não há barreiras ambientais físicas nas casas, nos edifícios, nos espaços ou equipamentos urbanos e nos meios de transporte individuais ou coletivos;

b)

Acessibilidade comunicacional: não há barreiras na comunicação interpessoal (face-a-face, língua de sinais), escrita (jornal, revista, livro, carta, apostila, incluindo textos em braile, uso do computador portátil) e virtual (acessibilidade digital);

c)

Acessibilidade metodológica: não há barreiras nos métodos e técnicas de estudo (escolar), de trabalho (profissional), de ação comunitária (social, cultural, artística etc) e de educação dos filhos (familiar);

d)

Acessibilidade instrumental: não há barreiras nos instrumentos, utensílios e ferramentas de estudo (escolar), de trabalho (profissional) e de lazer ou recreação (comunitária, turística ou esportiva);

e)

Acessibilidade programática: não há barreiras invisíveis embutidas em políticas públicas (leis, decretos, portarias) e normas ou regulamentos (institucionais, empresariais etc);

f)

Acessibilidade atitudinal: não há preconceitos, estigmas, estereótipos e discriminações.

A partir disso, nota-se que o debate em torno do conceito de acessibilidade possui uma aplicação direta com questões físicas e funcionais, tendo como resultado a busca pela eliminação de barreiras: arquitetônicas, comunicacional, metodológica, instrumental, pragmática e atitudinal, enfrentadas pelas pessoas com necessidades especiais.

Em suma, percebe-se que os conceitos de inclusão e acessibilidades não são iguais, mas possuem relações essenciais para a concretização de uma sociedade inclusiva, aliás, é a partir de ações que tornem todos esses quesitos de acessibilidade apresentados, reais em nossa sociedade, que será possível a inclusão dos indivíduos respeitando suas diferenças.

QUADRO 2 - Políticas Públicas de Educação no Contexto da Inclusão e Acessibilidade

\begin{tabular}{ccc}
\hline Política Públicas & Objetivo & Nível de Governo \\
\hline & O Programa Educação Inclusiva: Direito à Diversidade & \\
\hline
\end{tabular}




\begin{tabular}{lll}
\hline & é desenvolvido em todos os estados brasileiros e & \\
Programa & Distrito Federal pelo Ministério da Educação, e era \\
Educação & coordenado pela Secretaria de Educação Especial, com & Federal \\
Inclusiva: & sua extinção, o programa passou a ser uma ação da \\
Direito à & Secretaria de Educação Continuada, Alfabetização, \\
Diversidade & Diversidade e Inclusão. O Programa objetiva: \\
& Disseminar a política de construção de sistemas \\
& educacionais inclusivos e apoiar o processo de \\
& implementação e consolidação do Programa Educação \\
& Inclusiva: Direito à Diversidade nos municípios \\
& brasileiros.
\end{tabular}

Fonte: Elaborado pelo autor.

\subsection{Contexto da Gestão da Informação}

Segundo Lucas et al. (2008) com a evolução tecnológica ocorrida principalmente no final do século XX, a informação passou a desempenhar um papel fundamental na economia, sociedade e política tornando-se um recurso econômico utilizado pelas organizações em prol de uma melhor qualidade dos serviços e bens produzidos.

A partir disto, os processos de gerenciamento de informação/gestão da informação têm sido visto pelas organizações/instituições como um dos recursos fundamentais para o bom desempenho de suas atividades e satisfação dos seus clientes/usuários. Isto porque, segundo Beal (2004, p.7-8)

para serem eficazes, as organizações precisam ter seus processos decisórios e operacionais alimentados com informações de qualidade, obtidas dentro de uma boa relação de custo-benefício e adaptadas às necessidades do negócio (seja no setor privado, em instituições sem fins lucrativos ou no setor governamental).

Nesse sentido, gerenciar informação envolve um processo planejado de atividades com: a informação (coleta, organização, armazenagem, disseminação, disponibilização e uso), com as pessoas (utilizam, avaliam, dão sentido e condições de uso gerando o fluxo de informação na organização) e com os recursos informacionais e tecnológicos utilizados na otimização desse gerenciamento informacional (tecnologias de informação e comunicação, fontes e sistemas de informação etc.).

Pois como bem explicam Silva e Tomaél (2007, p. 1-2), a gestão da informação deve criar na instituição uma rede de inter-relacionamento entre seus diversos setores e unidades, permitindo dessa forma que o fluxo informacional seja direcionado para as atividades de gestão, aliás, trata-se de um processo social, onde as pessoas e suas relações são elementos fundamentais para a efetivação da gestão informacional. Além das pessoas, diferentes 
recursos de informação são mobilizados para que a gestão cumpra sua função. Esses recursos compreendem: tecnologia da informação, fontes, serviços e sistemas de informação.

A partir disso, considera-se aqui que a gestão da informação assim como o gerenciamento de qualquer outro recurso organizacional está alicerçada em um trabalho de planejamento tanto estratégico quanto operacional, pois permite segundo Beal (2004) fazer seu uso a partir de uma perspectiva situacional da organização (onde a informação é vista como suporte ao alcance de objetivos estratégicos) ou de uma perspectiva permanente (onde a informação é vista como recurso permanente de apoio as atividades diárias da organização).

Assim, de acordo com Valentim et al. (2008, p. 187):

Entende-se a gestão da informação como um conjunto de ações que visa desde a identificação das necessidades informacionais, o mapeamento dos fluxos formais (conhecimento explícito) de informação nos diferentes ambientes da organização, até a coleta, filtragem, análise, organização, armazenagem e disseminação, objetivando apoiar o desenvolvimento das atividades cotidianas e a tomada de decisão no ambiente corporativo. A gestão da informação, portanto, deve se preocupar com os documentos gerados, recebidos e utilizados para as atividades do negócio corporativo. A gestão documental ou gestão de documentos faz parte desse processo.

Ainda, segundo Beal (2004, p. 114), o processo de gestão da informação conta com funções de monitoramento, integração, otimização e redução de custos desempenhada pelas tecnologias de informação e comunicação arquitetadas em um sistema de informação, que permite entre outros aspectos:

a) A integração de dados e aplicações;

b) Automação de processos;

c) A capacidade de diagnósticos automáticos e de correção proativa de problemas; O trabalho cooperativo;

d) A troca de informações de modo seguro entre as organizações e entre estas e os consumidores de seus produtos e serviços.

QUADRO 3 - Políticas Públicas de Educação no Contexto da Gestão da Informação

\begin{tabular}{clc}
\hline Política & \multicolumn{1}{c}{ Objetivo } & Nível de Governo \\
Pública & \multicolumn{1}{c}{} & \\
Sistema & O Sistema Integrado de Gestão Educacional (SIGE) é & \\
Integrado de & o sistema de gerenciamento de informações da & \\
Gestão & Secretaria de Educação do Estado do Ceará - & Estadual \\
Educacional & SEDUC. Esse sistema foi desenvolvido em parceria &
\end{tabular}


(SIGE) com o CETREDE da Universidade Federal do Ceará, com o propósito de otimização e modernização dos processos administrativos e de compartilhamento e integração de informações entre as instituições de ensino e a SEDUC.

Sistema de O Sistema de Acompanhamento das Ações do Paic -

Acompanham SAAP, é um sistema de gerenciamento de ento das informações desenvolvido com o objetivo de coletar Ações do Paic informações e acompanhar as ações do Programa de (SAAP) Alfabetização na Idade Certa - PAIC.

O PAR é o planejamento multidimensional da

Plano de política de educação que os municípios, os estados e

Ação o DF devem fazer para um período de quatro anos.

Articulada Desse modo, O PAR é coordenado pelas secretarias

(PAR) municipais e estaduais de educação, contado com a participação de gestores, de professores e da comunidade local em seu processo de elaboração.

Fonte: Elaborado pelo autor.

\section{PROCEDIMENTOS METOdOLÓgicos}

Apresenta-se a seguir, os procedimentos metodológicos utilizados para classificar, descrever, direcionar, investigar e delimitar os rumos dessa pesquisa.

Assim sendo, quanto aos fins a pesquisa é de cunho exploratório e descritivo. Gil (2006, p. 41) explica que na maioria dos casos, a pesquisa exploratória envolve: "Levantamento bibliográfico; Entrevista com pessoas que tiveram experiências práticas com o problema pesquisado e; Análise de exemplos que "estimulem a compreensão". Em relação à pesquisa descritiva, Cervo, Bervian e Silva (2007, p. 61) explicam que "procura descobrir, com maior precisão possível, a frequiência com que um fenômeno ocorre, sua relação e conexão com outros, sua natureza e suas características".

Assim esses tipos de pesquisa se complementam e se aplicam adequadamente à proposta do estudo, pois se busca estabelecer uma possível interpolação das políticas públicas de informação no âmbito das políticas públicas de educação existentes na Secretaria Municipal de Educação de Juazeiro do Norte - CE.

Quanto aos meios, a pesquisa classifica-se como sendo bibliográfica e documental. É bibliográfica, pois utilizou-se de leitura, análise e interpretação de livros, monografias, dissertações, teses e artigos científico para construção do referencial teórico. É documental uma vez que foram utilizados documentos disponibilizados nos portais de comunicação do governo federal, estadual e municipal, para descrever e analisar as políticas públicas da Secretaria Municipal de Educação de Juazeiro do Norte, mencionadas no presente trabalho. 
No que se refere à natureza dos dados, sua análise foi realizada por meio de uma abordagem qualitativa, porque, através das estratégias de coletas de dados aqui estabelecidas, visa-se, sobretudo a "compreensão detalhada dos significados e características situacionais apresentadas pelos entrevistados, em lugar da produção de medidas quantitativas de características ou comportamentos" (RICHARDSON, 2011, p. 90).

Cabe ainda ressaltar que, para evitar certas limitações no processo de análise dos dados, por se tratar de uma pesquisa essencialmente de caráter qualitativo, foram estabelecidas categorias (inclusão digital, inclusão e acessibilidade e gestão da informação/gestão educacional) como parâmetros para tornar mais consistente a abordagem das informações apresentadas pelos sujeitos da pesquisa em equivalência com o referencial teórico apresentado. Complementando essa visão, ainda Richardson (2011, p. 80) destaca que:

Uma modalidade de transformar dados qualitativos em elementos quantificáveis, bastante empregada por pesquisadores, consiste em utilizar como parâmetros o emprego de critérios, categorias, escalas de atitude ou, ainda, identificar com que intensidade, ou grau, um conceito, uma atitude, uma opinião se manifesta.

O método utilizado para coletar os dados foi o indutivo, uma vez que adotou-se, como instrumentos de coleta de dados, a entrevista semi-estruturada, para extrair informações dos sujeitos da pesquisa sobre as políticas públicas de informação no contexto das políticas públicas de educação em estudo, a fim de extrair ao máximo dos entrevistados opiniões e fatos que possibilite analisar as percepções informacionais identificadas por esses sujeitos, no âmbito das políticas públicas da Secretaria Municipal de Educação de Juazeiro do Norte - CE, a partir das categorias de análise estabelecidas nesse trabalho (inclusão digital, inclusão e acessibilidade e gestão da informação), permitindo ao sujeito da pesquisa a liberdade em acrescentar informações que achem pertinente mediante as circunstâncias da pesquisa e do roteiro apresentado.

Com base nessa premissa, foram aplicadas as entrevistas com cada coordenador responsável pela execução dessas políticas na rede de educação do município de Juazeiro do Norte - CE, constando em um total de 6 entrevistados. Desse modo, cada entrevista foi estabelecida de acordo com as linhas de ação de cada política e direcionada aos seus coordenadores em particular. A entrevista está estruturada em 3 perguntas considerando os seguintes fatores:

a) A importância das políticas públicas de educação no contexto da: Inclusão digital, inclusão e acessibilidade e gestão educacional/gestão da informação;

b) As dificuldade e perspectivas de ação dessas políticas e; 
c) Sua relação com as demais políticas e atividades existente no âmbito da Secretaria e da rede de escolas do município.

Para identificar as respostas das entrevistas, utilizamos os seguintes códigos que correspondem a quantidade de coordenadores das políticas públicas envolvidos na investigação: $\mathrm{C} 1, \mathrm{C} 2, \mathrm{C} 3, \mathrm{C} 4, \mathrm{C} 5, \mathrm{C} 6$.

Consequentemente, ao conhecermos a realidade particular de cada uma dessas políticas, será permitido conceber de maneira mais consistente as discussões sobre as correlações existentes entre as políticas públicas de informação e educação.

\section{ANÁLISE E INTERPRETAÇÃO DOS DADOS}

A seguir, são apresentados e analisados os dados da pesquisa, sendo estabelecida a sua interpretação a partir dos pressupostos teóricos apresentados na introdução, no referencial teórico e nos procedimentos metodológicos que compreende esse trabalho.

\subsection{Das Políticas Públicas de Inclusão}

No contexto das políticas públicas de inclusão existente na Secretaria Municipal de Educação de Juazeiro do Norte, foram investigadas ações de inclusão digital e de inclusão e acessibilidade. Para tanto, foram realizadas entrevistas com os coordenadores responsáveis pela implementação das ações dessas políticas no município de Juazeiro do Norte.

Assim, com o propósito de perceber as considerações dos coordenadores do Projeto Interação Pedagógica e do Programa Nacional de Tecnologia Educacional (PROINFO) a respeito das políticas públicas de inclusão digital, fez-se a seguinte pergunta: Qual a importância das políticas públicas de educação no contexto da inclusão digital? $\mathrm{O}$ Quadro 4, a seguir, expõe as considerações feitas por esses coordenadores a respeito desta pergunta:

QUADRO 4 - Importância das políticas públicas no contexto da inclusão digital

\section{RESPOSTA}

C1 As políticas públicas tem um papel fundamental no processo de inclusão digital, pois os avanços tecnológicos vêm se desenvolvendo na sociedade desenfreadamente e as escolas públicas ainda não estão preparadas para lidar com estes avanços. Existem sérios problemas que implicam neste processo, tais como falta de estrutura física, capacitação dos profissionais e recursos financeiros para manutenção e aquisição de materiais necessários. Mesmo diante destas dificuldades, os alunos estão cada vez mais inseridos na era digital fora da escola, seja qual for sua classe social, e é impossível dissociar estes avanços de uma educação de qualidade. As políticas públicas existem justamente para promover esta interação social e digital, mas deve, contudo, buscar atender as dificuldades 


da cada região, cidade e município, visando realizar um trabalho significativo.
Sabemos que para alcançar um nível mais elevado de qualidade de ensino, se faz
necessário um grande investimento. Um dos passos a ser visto está na inclusão digital.
Não é preciso discutir o quão importante é o acesso as TICs para a alavancagem
econômica, cultural e social.

Fonte: Dados da pesquisa.

A partir da fala de $\mathrm{C} 1$, percebe-se que o processo de inclusão digital no município de Juazeiro do Norte nas escolas, ainda é um processo em construção, haja vista que muitas escolas não possuem infraestrutura adequada e, profissionais capacitados para $\mathrm{o}$ desenvolvimento de ações educativas que permitam aliar as práticas pedagógicas aos recursos digitais e eletrônicos.

Contudo, C1 afirma que, o processo de inclusão digital do educando vêm acontecendo de forma natural em decorrências das necessidades e exigências que as relações sociais fora da escola vêm influenciando, independentemente de suas condições financeiras. Isso demonstra que, o acesso a computadores, mesmo que não seja em casa, têm permitido a esses alunos interagirem e se integrarem às novas práticas de interação social por meio da internet.

Além disso, C1 destaca a importância das políticas públicas de inclusão digital como um processo de inclusão social, ao atenderem as novas demandas e necessidades que a sociedade contemporânea vem demonstrando em relação aos avanços tecnológicos.

Em uma visão complementar C2, destaca a importância das políticas públicas de inclusão digital como ferramenta estratégica no desenvolvimento educacional do nosso país. Isso porque, C2 enfatiza que as TICs têm causado grande influência nos fatores de desenvolvimento econômico, cultural e social.

Isso permite afirmar que o processo de inclusão digital por meio das ações governamentais (políticas públicas) precisa garantir o pleno desenvolvimento das sociedades, considerando a inclusão digital uma forma de inclusão social, pois o desenvolvimento econômico, cultural, político e social das sociedades têm sinalizado o papel preponderante que as Tecnologias de Informação e Comunicação (TICs) têm desempenhado nos mais diversos processos de interação e inclusão social dos indivíduos em sociedade como decorrência das novas demandas, necessidade e capacidades de cada sociedade em particular.

Ainda, no contexto das políticas públicas de inclusão digital, buscou-se tomar conhecimentos a respeito das dificuldades e perspectivas enfrentadas pelo Projeto de 
interação Pedagógica e Programa Nacional de Tecnologia Educacional (PROINFO). Sobre o Projeto de interação Pedagógica, indagou-se seu coordenador com a seguinte questão: Fale sobre a atuação (dificuldades e perspectivas) do Projeto de interação Pedagógica como políticas públicas de educação no contexto da inclusão digital no município de Juazeiro

do Norte. A resposta obtida encontra-se descrita no Quadro 5 abaixo:

QUADRO 5 - Dificuldades e perspectivas do Projeto Interação pedagógica no município de Juazeiro do Norte - CE RESPOSTA

C1 O Projeto Interação Pedagógica visa promover a interação das escolas no acompanhamento das atividades desenvolvidas no âmbito escolar com base no Projeto Político Pedagógico - PPP da escola. Desta forma este projeto veio somar na educação de Juazeiro do Norte com a iniciativa de identificar qual a realidade de cada instituição e agir de forma eficaz em cima das dificuldades por meio da formação de informática, utilizando as redes sociais como ferramenta metodológica para inclusão digital com base no interesse dos jovens e adolescentes. São inúmeros os problemas enfrentados para desenvolver este trabalho. Inicialmente podemos abordar a falta de estrutura física das escolas, que muitas vezes não possuem computador, internet e/ou até mesmo materiais de instalação elétrica para realizar a proposta. Ao todo são 107 escolas que serão incluídas neste projeto, entre elas de ensino infantil e fundamental. $\mathrm{Na} 1^{\mathrm{a}}$ fase de formação do projeto participaram 51 escolas da zona urbana, sendo 38 de ensino fundamental que já possuem internet e computadores e 13 escolas de ensino infantil, sendo que apenas 3 destas estão em condições físicas de participar, pois as demais encontram-se com problemas de falta de manutenção e ou problemas técnicos. É importante considerar também a falta de qualificação dos profissionais. Muitos não têm nenhuma noção de informática e ainda utiliza de métodos ultrapassados, o que leva o desinteresse dos educandos por não atender aos seus interesses. Outra dificuldade é a falta de investimento dos governantes em oferecer estrutura e recursos financeiros. Enfatizo que o trabalho realizado através do Projeto Interação Pedagógica é realizado com os coordenadores pedagógicos e muitas escolas não possuem este profissional, outras coordenadoras mudam frequentemente impedindo a continuidade do processo educativo, e muitas vezes também os profissionais sentem dificuldades relativas à falta de habilidade, falta de tempo e outros a falta de interesse em realizar a proposta. Embora existam várias dificuldades é importante destacar diversos benefícios que a implantação do Projeto Interação Pedagógica trouxe para nosso município. As escolas receberão maior acompanhamento pedagógico, subsídio teórico-prático para desenvolver suas ações dentro da proposta exigida pelo MEC de elevar o índice de aprendizagem. As escolas receberão um netbook e internet $3 \mathrm{G}$ para melhor desenvolver as ações, projetos e divulgar os eventos e acontecimentos importantes da escola, como também utilizar as redes sociais como ferramenta metodológica para incentivar os alunos e professores a interagir e promover a gestão participativa, visando apropriar-se dos interesses dos alunos e agir com base nisso. As 56 escolas que estão participando da $2^{\mathrm{a}}$ fase de formação são de educação infantil urbanas e rurais de ensino fundamental, e sentem-se excluídas do processo de inclusão digital pois não tem nenhum tipo de estrutura para esta. No caso destas escolas a conexão não cobre estas localidades. Portanto com o recebimento do moldem $3 \mathrm{G}$ móvel estas poderão estar conectadas e desenvolver suas atividades de forma condizente aos seus interesses. Considero que o processo de inclusão digital em Juazeiro do Norte está começando a dar os primeiros passos e o Projeto Interação Pedagógica está contribuindo para este desenvolvimento.

Precisamos ainda investir muito e qualificar o grupo de gestores escolares e se inteirar da realidade de cada escola para enfim poder estruturá-las para que estas possam enfim atingir os objetivos e integrassem neste processo tecnológico.

Fonte: Dados da pesquisa.

Com base nas afirmações feitas por $\mathrm{C} 1$, é pertinente dizer que o Projeto Interação Pedagógica têm importante significado no processo de inclusão digital do município de 
Juazeiro do Norte, pois vem construindo importantes significados e percepções dessas escolas para com as redes de interação social da internet, ao indicar caminhos e ações de utilização dessas ferramentas no processo de ensino-aprendizagem e compartilhamento de informações das instituições com a comunidade juazeirense, permitindo a construção e desenvolvimento de significados (construção de metodologias e estratégia de mediação de informação e conteúdos) e dispositivos informacionais (utilização das redes sociais).

Contudo, C1, destaca alguns desafios a serem enfrentados pelas escolas, para o pleno desenvolvimento das ações de inclusão digital por meio desse projeto:

a)

Falta de estrutura física (computadores, internet e materiais de instalação elétrica). Demonstrando a falta de investimento do governo, para garantir um processo mais profícuo de inclusão digital dessas escolas;

b) Falta de capacitação dos profissionais. Muitos educadores e gestores dessas instituições de ensino não possuem habilidade técnica e informacional que lhes permitam a construção de significados para o desenvolvimento de novas práticas pedagógicas a partir desses dispositivos;

c)

Mudança freqüente de coordenadores pedagógicos nas escolas. Com efeito, a continuidade das ações do projeto, fica prejudicada ao não permitir uma educação continuada desses profissionais no processo de capacitação.

Portanto, convém ressaltar que, o processo de inclusão digital em Juazeiro do Norte - CE em âmbito escolar caminha a passos lentos. Nesse sentido, verifica-se a necessidade de investimento por parte de seus gestores públicos em infraestrutura tecnológica, que permita o pleno desenvolvimento dos projetos de inclusão digital no ambiente escolar.

Contudo, através de projetos como o Interação Pedagógica são sinalizadas o desenvolvimento de estratégias que venham a garantir o acesso e a utilização de forma mais produtiva e efetiva das Tecnologias de Informação e Comunicação nas atividades de gestão, ensino e pesquisa escolar.

Em relação ao Programa Nacional de Tecnologia Educacional (PROINFO), também indagou-se seu coordenador com a seguinte questão: Fale sobre a atuação (dificuldades e perspectivas) do Programa Nacional de Tecnologia Educacional (PROINFO) como políticas públicas de educação no contexto da inclusão digital no município de Juazeiro do Norte. Sobre esta questão, obtivemos as seguintes considerações apresentadas no Quadro 6 a seguir: 
QUADRO 6 - Dificuldades e perspectivas do Programa Nacional de Tecnologia Educacional (PROINFO) no município de Juazeiro do Norte - CE

\section{RESPOSTA}

C2 Mesmo sabendo da grande importância para a qualidade de ensino a dificuldade maior ainda está na parte técnica (manutenção) das máquinas e o mito dos profissionais que ainda é grande. As perspectivas estão no leque aberto pelo MEC com os cursos de formação e inclusão digital, projetos portal do professor entre outros, com o apoio do gestor municipal.

Fonte: Dados da pesquisa.

No que tange à fala de $\mathrm{C} 2$, percebe-se que o desenvolvimento do PROINFO no município de Juazeiro do Norte enfrenta dois desafios:

a)

Falta de infra-estrutura tecnológica e;

b)

Falta de profissionais na área de tecnologias de informação e comunicação.

É lícito supor que as carências de infraestrutura tecnológica e profissionais que trabalham com tecnologias de informação e comunicação no município de Juazeiro do Norte são devido ao lento processo de inserção da cultura digital em nossa região, que ainda caminha a passos lentos. Contudo, o desenvolvimento tecnológico em nossa região já está sendo sinalizado pela chegada de cursos acadêmico-profissionais na área de tecnologias de informação e comunicação.

Isso demonstra que o PROINFO no município de Juazeiro do Norte é fundamental para o desenvolvimento e inserção da cultural tecnológico-digital no ambiente escolar, a partir dos educadores, propondo a utilização de tecnologias de informação e comunicação como ferramenta de apoio pedagógico na rede municipal de ensino da educação básica.

De acordo com as afirmações feitas por C2, compreende-se que o PROINFO traz grandes perspectivas de desenvolvimento tecnológico para nossa região, ao possibilitar que os educadores da rede pública de ensino básico desenvolvam habilidades tanto técnicas como informacionais a respeito da manipulação dessas ferramentas por meio dos cursos de capacitação oferecidos pelo MEC, desenvolvendo estratégias de inserção dessas ferramentas no processo de ensino-aprendizagem de acordo com as necessidades, interesses e demandas das instituições de ensino do município.

Já no que se refere às políticas públicas de inclusão e acessibilidade, foi realizada entrevista com o coordenador responsável pelo processo de implementação das ações e atividades do Programa Educação Inclusiva: direito á diversidade no município de 
Juazeiro do Norte, objetivando coletar informações a respeito da importância e da atuação da política de educação inclusiva em nosso município.

Para tanto, em uma primeira análise questionou-se o coordenador com a seguinte pergunta: Qual a importância das políticas públicas de educação no contexto da inclusão e acessibilidade? Sobre isto, obtivemos a seguinte resposta apresentada no Quadro 7 a seguir:

QUADRO 7 - Importância das políticas públicas no contexto da inclusão e acessibilidade

\begin{tabular}{l} 
RESPOSTA \\
\hline C3 \\
As políticas públicas de educação inclusiva dão longos passos consolidando-se com uma \\
educação de qualidade. Juazeiro vem avançando na questão acessibilidade para pessoas com \\
deficiência física ou mobilidade reduzida. Inclusão escolar significa assegurar o acesso ao \\
aluno com deficiência não somente à sala de aula, mas a todos os ambientes e serviços \\
disponíveis, possibilitando que o mesmo participe de atividades desenvolvidas na escola e \\
que aprenda juntamente com todos os outros alunos. Desta forma, deve ser acessível não \\
apenas a estrutura física da escola, mas todos os seus espaços, proporcionando condições de \\
utilização por todas as pessoas. Juazeiro tem algumas escolas que serão construídas com \\
acessibilidade. O governo federal viabiliza recursos financeiros para que haja esta \\
acessibilidade arquitetônica. Percebemos a importância das políticas públicas para que se \\
cumpra a lei n ${ }^{\circ} 10.098 / 00$ e ao decreto n ${ }^{\circ}$ 5.926/04 onde preconiza que não apenas a parte \\
estrutural deve ter acessibilidade, mas os transportes também.
\end{tabular}
Fonte: Dados da pesquisa.

A partir das colocações feitas por C3, compreende-se que as políticas públicas de educação no contexto da inclusão e acessibilidade têm o desafio de construir uma sociedade mais inclusiva a partir de um modelo de educação mais inclusivo e acessível para todos os indivíduos em sociedade, independentemente de suas limitações.

É, portanto, papel dos governos, garantir que pessoas com necessidades especiais sejam capazes de participarem do processo de ensino-aprendizagem sem qualquer prejuízo, sendo-lhes assegurado o processo de inclusão em salas de aula com outros alunos que possuam ou não necessidades especiais. Nesse sentido, é possível destacar as políticas públicas como importante instrumento de conscientização e construção coletiva de uma sociedade e educação mais inclusiva em nosso país, em que espaços físicos, produtos e serviços possuam estrutura acessível a todos. Assim, C3 enfatiza a importância das escolas e profissionais serem capacitados e preparados para atender as necessidades de todos os seus educandos.

Quanto à atuação do Programa Educação inclusiva: direito à diversidade, direcionouse a seu coordenador com a seguinte questão: Fale sobre a atuação (dificuldades e perspectivas) do Programa Educação inclusiva: direito à diversidade como políticas 
públicas de educação no contexto da inclusão e acessibilidade no município de Juazeiro

do Norte. Para efeito, conseguimos a seguinte resposta descrita no Quadro 8:

QUADRO 8 - Dificuldades e perspectivas do Programa de Educação Inclusiva: direito a diversidade no município de Juazeiro do Norte - CE

\begin{tabular}{l}
\hline RESPOSTA \\
\hline C3 O programa educação inclusiva: direito à diversidade tem como objetivo garantir o acesso e \\
a permanência de todas as crianças, jovens e adultos com deficiência, bem como disseminar \\
a política de construção de sistemas educacionais inclusivos e apoiar o processo de \\
implementação nos municípios brasileiros. O referido programa capacita gestores e \\
educadores dos municípios pólo para implementar a política de educação inclusiva no seu \\
município e nos municípios de sua área de abrangência. O governo federal através da \\
SECADI - Secretaria de educação continuada, alfabetização, diversidade e inclusão, \\
viabiliza este programa com recursos financeiros. Juazeiro do Norte é município pólo do \\
referido programa e tem 53 municípios em sua jurisdição.
\end{tabular}

Fonte: Dados da pesquisa

Partindo dessas afirmações feitas por C3, nota-se que o princípio fundamentador do Programa Educação Inclusiva: direito à diversidade, é conscientizar a sociedade para a construção de um sistema de educação inclusiva em nosso país.

Para tanto, o programa desenvolve ações de formação e capacitação de gestores e educadores municipais para serem multiplicadores do processo de disseminação da política de educação inclusiva no âmbito de seus municípios.

Com efeito, nota-se que o programa educação inclusiva desempenha importante ação na construção de significados informacionais por parte dos gestores e educadores envolvidos nesse processo de capacitação, por implantarem uma perspectiva de disseminação da política e do sistema de educação inclusiva a ser consolidadas pela educação do nosso país a partir de ações e experiências locais. Pois,

aqui a informação é qualificada como um instrumento modificador da consciência e da sociedade como um todo. Aqui a informação é qualificada como um instrumento modificador do homem e de seu grupo (BARRETO, 1994, p. 2).

\subsection{Das Políticas Públicas de Gestão da Informação}

Em relação às políticas públicas da Secretaria Municipal de Educação de Juazeiro do Norte, categorizadas no âmbito da gestão da informação, buscou-se realizar entrevistas com os coordenadores responsáveis pela coordenação bem como implementação das ações do Sistema Integrado de Gestão Educacional (SIGE), Sistema de Acompanhamento das Ações do Paic (SAAP) e do Plano de Ação Articulada (PAR), com o propósito de 
investigar processos de gerenciamento de informação a partir dessas políticas de gestão educacional desenvolvidas na rede municipal de ensino básico de Juazeiro do Norte.

Para tanto, indagou-se os coordenadores dessas políticas de maneira geral com a seguinte pergunta: Qual a importância das políticas públicas de educação no contexto da gestão educacional? Sobre isto, obtivemos as afirmações, expostas no Quadro 9 a seguir:

QUADRO 9 - Importância das políticas públicas no contexto da gestão da informação educacional

\section{RESPOSTA}

C4 Facilitar o acesso e a visão geral da escola em tempo real. O SIGE possibilita o armazenamento de dados fundamentais ao acompanhamento das ações da gestão escolar. É uma ferramenta de integração online.

C5 O SAAP da uma visão de como está o aluno do $1^{\circ}$ e $2^{\circ}$ ano, facilitando o acompanhamento da aprendizagem do aluno. Trabalhamos com 62 escolas.

C6 A proposta da nova forma de se fazer políticas públicas, ocorrida no Brasil a partir dos parâmetros da nova Constituição Federal, efetivamente mais democrática, permite que a gestão pública deva abrir espaços para a participação popular, portanto, estruturando uma forma de gestão significativa e democrática. Importante, portanto, quando permite um exercício de cidadania, onde a população encontra espaço para colaborar com as decisões gestoras, inclusive, com a gestão financeira pública. É um exercício de autonomia e responsabilidade coletiva.

$$
\text { Fonte: Dados da pesquisa. }
$$

A partir da fala de C4, nota-se que a importância das políticas públicas de educação no contexto da gestão escolar foi estabelecida a partir das vantagens do Sistema Integrado de Gestão Educacional (SIGE). Isso faz supor que as políticas públicas de educação referentes à gestão educacional têm como uma de suas linhas de ação criar canais de informação através da implantação de sistemas de informação que primem pelo gerenciamento de informações e das ações das escolas de forma participativa, democrática e eficaz.

Logo, é nítido que o processo de compartilhamento de informações referentes à situação e ações desenvolvidas no âmbito dessas instituições, pode ser caracterizado como um processo de gestão da informação, pois o armazenamento, compartilhamento e gerenciamento de informações nesse sistema representa esse processo.

Ainda, percebe-se que o SIGE se configura como uma ferramenta de ação estratégica entre as escolas e a secretaria de educação do município, ao permitir através desse compartilhamento de informações o delineamento de ações profícuas ao aperfeiçoamento do ensino-aprendizagem.

De modo similar, C5 fala do Sistema de Acompanhamento das Ações do Paic (SAAP) como uma importante ferramenta estratégica de avaliação e acompanhamento da 
aprendizagem do aluno. Em outras palavras, C6 busca relacionar a importância das políticas públicas de educação no contexto da gestão educacional à reforma da Constituição Federal ocorrida em 1988.

Nesse sentido, percebe-se que C6 visualiza a política pública como uma ferramenta de gestão participativa, onde a gestão pública com base nos novos parâmetros da constituição brasileira encontra justificativas e estratégias para criar canais participativos que permitam a atuação da população nos processos decisórios sobre a implementação dos recursos públicos.

Partindo desse ponto de vista, é evidente que a criação de canais participativos se configura em um importante instrumento de controle social, integração e compartilhamento de informações entre a gestão pública e a sociedade em geral, permitindo o exercício da cidadania.

Conseguinte, buscou-se tomar conhecimentos a respeito das dificuldades e perspectivas enfrentadas pelo SIGE em seu processo de implementação no município de Juazeiro do Norte.

A respeito disso, indagou-se seu coordenador com a seguinte pergunta: Fale sobre a atuação (dificuldades e perspectivas) do Sistema Integrado de Gestão Educacional (SIGE) como políticas públicas de educação no contexto da gestão educacional no município de Juazeiro do Norte. A resposta obtida encontra-se descrita no Quadro 10 abaixo:

QUADRO 10 - Dificuldades e perspectivas do Sistema integrado de gestão educacional no município de Juazeiro do Norte - CE

\begin{tabular}{l}
\hline RESPOSTAS \\
\hline D4 Dificuldades: a) Escolas sem computadores e internet; b) Secretários sem curso de \\
informática (não sabem usar o computador); c) Área rural sem sinal para usar internet por \\
conta das antenas (no caso, se utilizam dos equipamentos da secretaria de educação). \\
Perspectivas: a) Laboratórios de informática em todas as escolas; b) Acesso a internet; c) \\
Sinal e acesso a internet para área rural.
\end{tabular}

Fonte: Dados da pesquisa.

Com base nessa fala de C4, ficou evidente que a atuação do SIGE no ambiente dessas escolas é comprometida pela falta de infraestrutura básica, necessárias ao pleno funcionamento desse sistema para armazenamento e integração de dados. 
Ainda, a falta de habilidade técnico-operacional para uso de computadores por parte dos gestores escolares, afeta o processo de compartilhamento e integração dos dados necessários ao planejamento de ações para essas escolas por parte da secretaria de educação.

Assim podemos definir esses fatores como barreiras socioeconômicas e culturais na utilização de tecnologias de informação e comunicação no contexto escolar do município de Juazeiro do Norte. Podemos então definir essas barreiras como:

a)

A usabilidade (aqui implica a relação homem-máquina a partir das facilidades de manuseio do computador e do SIGE, para realização das tarefas de forma precisa, eficiente e eficaz, satisfatórias as demandas). Ou seja, percebe-se a necessidade de alfabetização digital para melhor utilização dos recursos tecnológicos;

b) A falta de investimento por parte do governo em infraestrutura tecnológica que garanta o acesso e uso desses meios eletrônicos e digitais de informação e comunicação dentro do ambiente escolar.

Dessa forma, ainda de acordo com C4 a superação dessas barreiras, que implicarão em uma utilização mais profícua dessa tecnologia (SIGE) dentro dos ambientes escolares está na implantação de infraestrutura básica (computadores e internet) tanto na zona rural como urbana que garantam o acesso e uso dessas tecnologias pelos educadores, educando e gestores educacionais do município de Juazeiro do Norte - CE.

De forma complementar e opcional (pelo entrevistado), ainda em relação ao SIGE buscou-se saber sobre as possíveis relações existentes entre o SIGE e outras políticas desenvolvidas pela Secretaria Municipal de Educação. Fez-se essa indagação pelas seguintes razões:

a) Observar ações similares e complementares entre as políticas públicas dessa secretaria abordadas nesse trabalho e;

b) Tomar conhecimento de outras políticas desenvolvidas pela Secretaria Municipal de Educação que não tenham sido abordadas nesse trabalho.

QUADRO 11 - Políticas que possuem relação com o SIGE

RESPOSTA

C4 a) PDDE interativo

b) Interação pedagógica

Fonte: Dados da pesquisa. 
De acordo com C4, outras políticas educacionais existentes na Secretaria Municipal de Educação que possuem relações com o SIGE é o PDE interativo e o Interação Pedagógica.

O Projeto Interação pedagógica foi abordado nesse trabalho no âmbito das políticas públicas de inclusão digital, e percebe-se que possui ações semelhantes ao SIGE no que diz respeito ao processo de compartilhando de informações dos Projetos Políticos Pedagógicos e ações desenvolvidas pelas escolas municipais de Juazeiro do Norte - CE.

Portanto, é pertinente também uma atividade de gerenciamento de informações educacionais a partir das redes de colaboração coletiva da internet (as redes sociais), visando facilitar e aprimorar o acesso e uso de informações por parte dos gestores educacionais e comunidade escolar, fundamentais para o planejamento e implementação de novas ações e aperfeiçoamento das ações já em curso.

Em relação ao PDE interativo, percebe-se uma relação ainda mais próxima por ser também uma ferramenta de planejamento da gestão educacional, operacionalizada por meio de um sistema de gerenciamento de informações, o SIMEC - Sistema de Planejamento e Monitoramento do Ministério da Educação.

Complementando essa visão, o Portal de informações do PDE Escola afirma que:

O PDDE Interativo é a ferramenta de planejamento da gestão escolar disponível no SIMEC para todas as escolas públicas. Ele foi desenvolvido pelo Ministério da Educação em parceria com as secretarias estaduais e municipais e sua principal característica é a natureza auto-instrucional e interativa de cada tela. Ou seja, além das escolas e secretarias não precisarem mais realizar formações presenciais para conhecer a metodologia e utilizar o sistema, este interage permanentemente com o usuário, estimulando a reflexão sobre os temas abordados. As mudanças tiveram como principal objetivo facilitar o acesso e a navegação da equipe escolar e de todas as pessoas interessadas em conhecer a ferramenta. ${ }^{4}$

Portanto, o PDE interativo é uma ferramenta de planejamento da gestão escolar que tem como principal estratégia o desenvolvimento de diagnósticos de situação para o aperfeiçoamento do processo de ensino-aprendizagem e definição de ações para que as escolas possam alcançar seus objetivos estratégicos melhorando a qualidade dos seus resultados.

Assim, é notória as suas relações com o SIGE no que diz respeito ao processo de armazenamento de dados no SIMEC, acesso e uso das informações para a elaboração e

\footnotetext{
${ }^{4}$ Informação extraída do Portal PDE Escola. Disponível em <http://pdeescola.mec.gov.br/pde-interativo>.
} 
desenvolvimento de planos e ações estratégicas que primem pelo aperfeiçoamento do ensino-aprendizagem e da gestão educacional.

Ainda sobre o SIGE, seu coordenador teceu alguns comentários adicionais na entrevista sobre os processos técnico-operacionais do sistema, apresentados no Quadro 12 abaixo:

\section{QUADRO 12 - Funções do Sistema Integrado de Gestão Educacional (SIGE)}

\begin{tabular}{l} 
RESPOSTA \\
\hline C4 O SIGE através da internet viabiliza o acompanhamento da utilização dos recursos físicos e \\
da matrícula do aluno, do desempenho acadêmico e da freqüência do mesmo por parte dos \\
gestores educacionais e escolares. Com esses dados os gestores conseguem avaliar e planejar \\
as políticas de educação. No momento estamos trabalhando somente com o módulo \\
acadêmico. Vão abrir os módulos: lotação (visão do quantitativo de professores com carga \\
horária e respectivas turmas) e rede física (compreendendo toda a estrutura física das escolas) \\
no próximo mês. Com isso iremos perceber as turmas através do módulo acadêmico, a \\
estrutura física e os professores dessas turmas através do módulo lotação. Tendo como \\
planejar as futuras demandas (professores e alunos).
\end{tabular}

Fonte: Dados da pesquisa.

Com base no exposto por C4, fica claro que o Sistema Integrado de Gestão Educacional o SIGE, possibilita:

a)

Melhoria no acesso às informações das escolas, propiciando o compartilhamento de informações de forma mais precisa e rápida, exigindo dos gestores educacionais um menor esforço para coletar informações necessárias ao planejamento e elaboração e implementação de novas políticas;

b)

Avançar na oferta e demanda de serviços ao permitir a visualização da utilização do espaço físico da escola e dos recursos humanos (professores e suas respectivas cargas horárias e turmas, bem como número de alunos por turmas);

c)

O desenvolvimento de melhores estratégias na tomada de decisões, por meio do fornecimento de informações mais rápidas e precisas, facilitando ainda a elaboração de planos, relatórios e diagnósticos de situação necessários ao aperfeiçoamento das ações desenvolvidas pelas escolas e implantação de recursos advindas do Governo Federal, Estadual e Municipal;

d)

Otimização de competências dos gestores educacionais, de acordo com a estrutura organizacional de cada escola, facilitando o fluxo de informações entre a escola e seus setores de atividades e a secretaria municipal de educação. 
No que se refere ao Sistema de Acompanhamento das Ações do PAIC, também buscou-se coletar informações sobre seu procedimento de atuação em Juazeiro do Norte, indagando seu coordenador com a seguinte questão: Fale sobre a atuação (dificuldades e perspectivas) do Sistema de Acompanhamento das Ações do Paic (SAAP) como política pública de educação no contexto da gestão educacional no município de Juazeiro do Norte. Com isso, tivemos as seguintes afirmações apresentadas no Quadro 13 a seguir:

QUADRO 1 - Dificuldades e perspectivas do Sistema de Acompanhamento das Ações do Paic (SAAP) no município de Juazeiro do Norte

\begin{tabular}{l}
\hline \multicolumn{1}{c}{ RESPOSTA } \\
\hline C5 Dificuldade: a) Falta de acesso a laboratório de informática e internet; b) Falta de habilidade \\
de alguns em manipular os aparelhos. Perspectivas: a) Habilitar os coordenadores \\
pedagógicos das unidades escolares da rede municipal.
\end{tabular}

Fonte: Dados da pesquisa.

Com referência a fala de C5, fica evidente que as dificuldades enfrentadas para implementação mais efetiva do SAAP encontram-se na falta de investimento governamental em infraestrutura tecnológica para as escolas, além da falta de treinamento e habilidade por parte dos gestores educacionais para utilização dos computadores.

Portanto, coloca-se como fundamental não apenas o investimento financeiro por parte do governo em equipar as escolas com computadores, pois, esse processo não garante por si só as habilidades necessárias para manipulação do SAAP, mas também verifica-se a necessidade de promover cursos de capacitação que garantam o desenvolvimento de habilidades necessárias aos gestores educacionais do município de Juazeiro do Norte para manipular o computador e o sistema de informação SAAP.

Já na indagação sobre as políticas públicas que possuem relação com o SAAP, obtivemos do entrevistado a seguinte resposta, descrita no Quadro 14:

QUADRO 2 - Políticas que possuem relação com o SAAP

\begin{tabular}{ll}
\hline & \multicolumn{1}{c}{ RESPOSTA } \\
\hline C5 & PDE Interativo \\
& Interação pedagógica \\
& SIGE
\end{tabular}

Fonte: Dados da pesquisa.

Nesse sentindo, percebe-se, portanto que essas relações são estabelecidas a partir: 
a)

Do uso intensivo das tecnologias de informação e comunicação para o desenvolvimento das ações dessas políticas e fornecimento de informações de forma rápida e precisa;

b) Do processo de gerenciamento e compartilhamento de informações educacionais das unidades escolares do município, propiciando a elaboração de relatórios e planejamentos de ação políticas e pedagógicas de acordo com as carências, capacidades, interesses e metas de cada unidade escolar;

c) Melhoria no processo de interação entre as unidades escolares e a secretaria municipal de educação de Juazeiro do Norte.

Por fim, o entrevistado C5, ainda forneceu algumas informações adicionais sobre o SAAP, no que se refere a sua função e arquitetura de informação, apresentadas no Quadro 15 abaixo:

\section{QUADRO 15 - Funções e arquitetura do SAAP}

\begin{tabular}{l}
\hline RESPOSTA \\
\hline C5 No SAAP encontra-se os indicadores: População; Fontes de financiamento da educação; \\
Resultado de avaliações externas; A meta da educação; No de matrículas turma e professores, \\
relacionados ao PAIC. \\
O SAAP oferece relatórios de freqüência de aluno, professor, servidor, dias letivos por \\
semestre, registro da quantidade de títulos lidos de literatura infantil pelos alunos (recebem \\
coleções de literatura infantil); a situação de leitura das crianças. Dentro do plano de ação do \\
município existem as metas que são do eixo: a) Da gestão municipal de educação; b) Da \\
alfabetização; Da educação infantil; c) Da literatura infantil e formação do leitor; d) Da \\
avaliação externa.
\end{tabular}

$$
\text { Fonte: Dados da pesquisa. }
$$

A partir dessas colocações feitas por C5, percebe-se que o sistema de informação SAAP, permite o controle, avaliação e acompanhamento das ações do PAIC, propiciando o desenvolvimento de ações pedagógicas para aperfeiçoamento do ensino-aprendizagem de forma mais precisa de acordo com os resultados apresentado por cada aluno e com as metas estabelecidas pelo plano de ação municipal referente a cada eixo de ação destacados na fala do entrevistado.

Logo, fica demonstrado que o SAAP, enquanto sistema de gerenciamento de informações permite:

a) Integração de informações entre as escolas e a secretaria de educação;

b) Fornecimento de informações de forma rápida, facilitando o desenvolvimento de diagnósticos e relatórios; 
d)

e)

Informações detalhadas sobre o índice de alfabetização e leitura dos alunos; Fornecimento de melhores projeções dos efeitos da implantação do PAIC.

De modo similar, também questionou-se o coordenador do Plano de Ação Articulada - PAR, sobre a sua atuação no município de Juazeiro do Norte através da seguinte questão: Fale sobre a atuação (dificuldades e perspectivas) do Plano de Ação Articulada (PAR) como política pública de educação no contexto da gestão educacional no município de Juazeiro do Norte. Para efeito, coletamos a seguinte resposta exposta no Quadro 16:

QUADRO 16 - Dificuldades e perspectivas de atuação do Plano de cão Articulada no Município de Juazeiro do Norte

\begin{tabular}{l}
\hline RESPOSTA \\
\hline C6 \\
As maiores dificuldades do Plano de Ações Articuladas - PAR, acontecem a partir da sua primeira etapa, \\
ou seja, a elaboração. Pensar políticas públicas no tocante a educação já é uma tarefa complexa. Elaborar \\
um plano que envolva ações para um plurianual de quatro anos, considerando, inclusive a transição \\
administrativa (o PAR é estruturado para ser executado nos últimos três anos de uma gestão municipal e \\
no primeiro ano posterior às eleições municipais), é uma grande responsabilidade para a equipe da \\
Secretaria Municipal de Educação que recebe a incumbência de planejar ações que envolvam todos os \\
segmentos e que resultem em melhoria de qualidade de ensino e aprendizagem. A execução das ações \\
também envolve uma série de fatores como: transporte, pessoal qualificado, infraestrutura física e \\
pedagógica, etc. Embora o PAR se apresente como um plano que envolve um considerável nível de \\
dificuldade para ser estruturado, apresenta-se como uma das mais efetivas ferramentas de melhoria de \\
qualidade do processo de ensino e aprendizagem, pois permite que os municípios recebam apoio, tanto \\
técnico quanto financeiro, de forma democrática e exerçam liberdade de atuação de acordo com a sua \\
realidade.
\end{tabular}

Fonte: Dados da pesquisa.

A partir das afirmações feitas pelo entrevistado C6, verifica-se que Plano de Ação Articulada - PAR é um instrumento de avaliação e de implementação de políticas, que objetiva a melhoria da qualidade da educação básica. Para tanto, são desenvolvidos relatórios ou diagnósticos de situação baseada nos diversos segmentos de atuação das políticas públicas existentes na Secretaria Municipal de Educação com base nos resultados e informações dos desempenhos apresentados pelo município a partir dessas políticas.

Assim, pode-se dizer que o PAR é um importante instrumento de gestão da informação educacional, pois busca desenvolver uma análise bem como apresentação de resultados em linhas gerais, sobre os avanços e retrocessos ocorridos na rede municipal de educação básica de Juazeiro do Norte - CE, tendo por objetivo sinalizar a necessidade do desenvolvimento de novas estratégias para melhoria da qualidade da educação com base nas carências, interesses e metas particulares do município.

É um instrumento de planejamento que gera conhecimento a partir de informações obtidas da realidade em estudo por parte dos gestores educacionais responsáveis pela sua 
elaboração bem como diagnóstico; esses por sua vez tornam-se os agentes criativos responsáveis pelo processo de inovação a partir da elaboração e implementação de novas estratégias.

Complementando essa visão, Rezende (2002, p. 121) afirma que os agentes criativos "são os profissionais que utilizam a informação na solução de problemas, ou como insumo gerador de idéias que irão fundamentar novas tecnologias e conceitos que, por sua vez, irão proporcionar vantagem competitiva."

Contextualizando essa fala a realidade posta por esse trabalho, o Plano de Ação Articulado - PAR, portanto, seria o instrumento de mediação da informação, e os gestores educacionais da Secretaria Municipal de Educação de Juazeiro do Norte os agentes criativos responsáveis pela utilização dessas informações para fundamentar novas políticas educacionais na solução dos problemas, proporcionando a melhoria da qualidade da educação do município.

\section{CONSIDERAÇõES FINAIS}

Buscou-se, a partir do referencial teórico dessa pesquisa, contextualizar a importância da informação no atual aspecto econômico e social, e o papel do Estado frente às complexidades informacionais contemporâneas, a partir do conceito de política pública de informação. Nessa perspectiva, procurou-se realizar uma contextura entre política pública de informação e política pública de educação através dos seguintes parâmetros: Inclusão digital, inclusão e acessibilidade e gestão da informação, tendo como objeto de estudo as políticas públicas da Secretaria Municipal de Educação de Juazeiro do Norte.

Destarte, ao contextualizar e analisar essas políticas mediante tais parâmetros pôdese perceber que as políticas públicas de educação são dotadas de importantes significados informacionais, tendo potencial para desenvolver habilidades informacionais necessárias ao desenvolvimento dos indivíduos dentro da nova dinâmica da sociedade contemporânea.

Porém, no que se refere à realidade do município de Juazeiro do Norte, contexto onde essas políticas foram analisadas, ficou evidenciado que para tanto, ainda é necessário o investimento por parte do governo em infraestrutura informacional e tecnológica que garantam o melhor desempenho e percepção desses significados informacionais na realidade educacional do município. 
Além disso, ao analisar as políticas públicas sociais da Secretaria Municipal de Educação de Juazeiro do Norte, foi possível perceber as relações temáticas entre essas políticas, permitindo identificar dificuldades e perspectivas semelhantes no que se refere à atuação e implementação dessas políticas no município. Destacar essas relações é de fundamental importância para percebermos que mesmo com linhas de atuações diferentes, essas políticas têm enfrentado problemáticas semelhantes mediante a falta de infraestrutura adequada que impossibilitam um maior sucesso em seu campo de atuação. Além disso, é preciso ponderar que problemáticas sociais e educacionais interferem de forma negativa no processo de desempenho das atividades dos programas e projetos inibindo o potencial de eficácia junto à população.

Assim, sobre as políticas públicas de inclusão e gestão da informação, pode-se destacar alguns pontos semelhantes no que se refere as dificuldades e perspectivas de atuação dessas políticas, mediante a fala de seus coordenadores, a saber: a) Falta de infraestrutura tecnológica nas escolas (computadores, internet) tanto da zona urbana quanto rural. Impedindo que as atividades de capacitação e formação sejam realizadas no ambiente escolar, além de ser um impeditivo para o processo de implementação de ideias e conhecimentos adquiridos pelos cursos de capacitação oferecidos pelos programas e projetos. (Interação Pedagógica, ProInfo, SIGE e SAAP); b) Falta de usabilidade, o que impede o melhor desempenho na manipulação de computadores e no uso e recuperação de conteúdos disponibilizados por meio das ferramentas digitais, seja na internet ou nos sistemas de gerenciamento de informação. (Interação Pedagógica, ProInfo, SIGE e SAAP).

Ainda é valido ressaltar uma diferença fundamental percebida entre as políticas públicas de inclusão digital, inclusão e acessibilidade e gestão da informação: os termos usabilidade e acessibilidade. Enquanto o termo usabilidade foi identificado nas políticas de inclusão digital e gestão da informação para se referir mais às expectativas e o desenvolvimento de habilidade dos usuários em entender e perceber as estratégias de manipulação e uso dos softwares e redes sociais da internet, a acessibilidade está voltada mais para as condições de uso e inclusão dos sujeitos no meio escolar para usufruir das infraestruturas física, informacional e tecnológica. Essas diferenças conceituais envolvem as seguintes políticas: Interação Pedagógica, ProInfo, SIGE, SAAP (Usabilidade) e Educação inclusiva: direito à diversidade (Acessibilidade). 
Por tudo isso, percebe-se o quanto os programas e projetos de educação são importantes para promover o desenvolvimento social dos municípios de forma a atender as especificidades, necessidades e carências locais. Mesmo que o município de Juazeiro do Norte não possua uma infraestrutura de informação definida em seu âmbito educacional, é pertinente ressaltar que os programas e projetos existentes na Secretaria Municipal de Educação podem ser instrumentos estratégicos para se pensar uma política pública de informação efetiva no âmbito educacional do município, pois suas propostas apresentam indícios no tocante às grandes preocupações sociais contemporâneas ocasionadas pelo desenvolvimento científico e tecnológico.

\section{REFERÊNCIAS}

BARreto, A. A. A questão da informação. São Paulo em Perspectiva, São Paulo, v. 8, n. 4, p. 3-8, 1994. Disponível em: 〈http://www.alternex.com.br/ aldoibict/quest/quest.htm>. Acesso em 26 fev. 2012.

BEAL, A. Gestão estratégica da informação: como transformar a informação e a tecnologia da informação em fatores de crescimento e de alto desempenho nas organizações. São Paulo: Atlas, 2004.

BONILLA, M. H. S. Educação e inclusão digital, 2002. Disponível em: $<$ http://seminarioscientificos.dcc.ufba.br/pub/Inclusao/Documentos/bonillaeducacaoeinclusaodigital.rtf. > Acesso em: 20 abr. 2012.

BRANCO, M. A. F. Política nacional de informação em saúde no Brasil: um olhar alternativo, 2001. Tese (Doutorado em Medicina Social) - Instituto de Medicina Social Universidade Estadual do Rio de Janeiro, Rio de Janeiro, 2001.

BRASIL. Ministério da Educação e Cultura. PDDE interativo. Disponível em: <http://pdeescola.mec.gov.br/pde-interativo> Acesso em: 20 maio 2012. 
CABEDA, M. Inclusão digital e educação on-line em prol da cidadania: pontos para reflexão. Revista Brasileira de Aprendizagem Aberta e a Distância, São Paulo, fev. 2004.

CARVALHO, A. M. G. A apropriação da informação: um olhar sobre as políticas públicas sociais de inclusão digital. 2010. 169 f. Tese (Doutorado em Ciência da Informação) - Faculdade de Filosofia e Ciências, Universidade Estadual Paulista, 2010.

CERVO, A. L.; BERVIAN, P. A.; SILVA, R. Metodologia científica. 6. ed. São Paulo: Pearson Prentice Hall, 2007.

FERREIRA, Rubens da Silva. A sociedade da informação no Brasil: um ensaio sobre os desafios do Estado. Ciência da Informação, Brasília, v. 32, n. 1, p. 36-41, jan./abr. 2003.

GIL, A. C. Como elaborar projetos de pesquisa. 4. ed. São Paulo: Atlas, 2006.

GODOY, A. et. al. Cartilha de inclusão. 2000. Disponível em: < file:////Komm15/arquivos/Portal da Inclusao/site/0...200907/TEXTOS-INFORMATIVOS/CARTILHA DA INCLUSÃO.htm> Acesso em: 04 maio 2012.

GONZÁLEZ DE GÓMEZ, M. N. Da política de informação ao papel da informação na política contemporânea. Revista Internacional de Estudos Políticos, Rio de Janeiro, v. 1, n. 1, p. 21-32, 1999.

GUIMARÃES, T. O que não é inclusão digital. Disponível em: <www.cirandabrasil.net/03/materia.php?id_materia=96>. Acesso em: 30 mar. 2012.

JAMBEIRO, O.; SILVA, H. P. Políticas de Informação: digitalizando a inclusão social. Estudos de Sociologia, Araraquara, 17, p. 147-169, 2004.

JARDIM, J. M.; SILVA, S. C. A.; NHARRELUGA, R. S. Análise de políticas públicas: uma abordagem em direção as políticas públicas de informação. Perspectiva em Ciência da Informação, v. 14, n. 1, p. 2-22, jan./abr. 2009. 
LUCAS, A. et al. Estudo de usuário como estratégia para gestão da informação e do conhecimento: um estudo de caso. Revista ACB: Biblioteconomia em Santa Catarina, Florianópolis, v.13, n.1, p.59-79, jan./jun., 2008.

MARTELETO, R. M. Conhecimento e sociedade: pressupostos da antropologia da informação. In: AQUINO, M. A. O campo da ciência da informação: gênese, conexões e especificidades. João Pessoa: Ed. Universitária, 2002. p. 101-115.

MELO, A. M. Acessibilidade e desing universal. In: PUPO, D. T.; MELO, A. M.; FERRÉS, S. P. Acessibilidade: discurso e prática no cotidiano das bibliotecas. Campinas: SBUUNICAMP, 2006. p. 17-20.

MÍDIA E DEFICIÊNCIA. Brasília: Andi, Fundação Banco do Brasil, 2003. (Série Diversidade). Disponível em: < http://serv01.informacao.andi.org.br/25ddd12e_117460dd374_-7ffe.pdf> Acesso em: 10 maio 2012.

PASSERINO, L. M.; MONTARDO, S. P. Inclusão social via acessibilidade digital: Proposta de inclusão digital para Pessoas com Necessidades Especiais. Revista da Associação Nacional dos Programas de Pós-Graduação em Comunicação, abr., 2007. Disponível em: <www.compos.com.br/e-compos> Acesso em: 04 abr. 2012.

PERROTTI, E.; PIERUCCINI, I. Infoeducação: saberes e fazeres da contemporaneidade. In: LARA, M. L. G.; FUGINO, A.; NORONHA, D. P. (Org.). Informação e contemporaneidade: perspectivas. Recife: Néctar, 2007. p. 45-98.

PIERUCCINI, I. A ordem informacional dialógica: estudos sobre a busca de informação em educação. São Paulo: USP, 2004, 232f. Tese (Doutorado em Ciência da Informação) Escola de Comunicações e Artes, Universidade de São Paulo, 2004. 
REZENDE, Y. Informação para negócios: os novos agentes do conhecimento e a gestão do capital intelectual. Ciência da Informação, Brasília, v. 31, n. 2, p. 120-128, maio/ago. 2002.

RIBAS, C. S. C.; ZIVIANI, P. O profissional da informação: rumos e desafios para uma sociedade inclusiva. Informação \& Sociedade: Estudos, João Pessoa, v. 17, n. 3, p. 47-57, set./dez. 2007.

RICHARDSON, R. J. Pesquisa social: métodos e técnicas. 3. ed. São Paulo: Atlas, 2011.

RONDELLI, E. Quatro passos para a inclusão digital. Revista I-Coletiva, jun. 2003. Disponível em: <http://www.icoletiva.com.br/secao.asp?tipo=editorial\&id=9>. Acesso em: 30 mar. 2012.

SILVA, A. C. Educação e tecnologia: entre o discurso e a prática. Ensaio: avaliação e políticas públicas em educação, Rio de Janeiro, v. 19, n. 72, p. 527-554, jul./set. 2011.

SILVA, T. E. Política de Informação na pós-modernidade: reflexões sobre o caso do Brasil. Informação \& Sociedade: Estudos, João Pessoa, v.1, n.1, p.8-13, jan./dez. 1991.

SILVA, H. et. al. Inclusão digital e educação para a competência informacional: uma questão de ética e cidadania. Ciência da Informação, Brasília, v. 34, n. 1, p.28-36, jan./abr. 2005.

SILVA, T. E.; TOMAÉL, M. I. A gestão da informação nas organizações. Informação \& Informação, Londrina, v. 12, n. 2, jul./dez. 2007.

TORRES, E. F.; MAZZONI, A. A.; ALVES, J. B. M. A acessibilidade à informação no espaço digital. Ciência da Informação, Brasília, v. 31, n. 3, p. 83-91, set./dez. 2002.

VALENTIM, M. L. P. et al. Gestão da informação utilizando o método informapping. Perspectiva em Ciência da Informação, v. 13, n. 1, p. 184-198, jan./abr. 2008. 


\section{Como citar este artigo:}

PEREIRA, Naira Michelle Alves; SILVA, Jonathas Luiz Carvalho. Políticas públicas de informação no contexto da inclusão e gestão da informação: uma análise sobre as políticas públicas da secretaria municipal de educação de juazeiro do norte - CE. Rev. digit. bibliotecon. cienc. inf., Campinas, SP, v.13, n.1, p.06-41, jan/abr. 2015. ISSN 1678-765X. Disponível em:

<http://www.sbu.unicamp.br/seer/ojs/index.php/rbci>. Acesso em: 31 Jan. 2015. 